Article

\title{
Cross-Regulation Assessment of DIDO Buck-Boost Converter for Renewable Energy Application
}

\author{
Deepak Elamalayil Soman * (1) and Mats Leijon \\ Division of Electricity, Department of Engineering Sciences, Angstrom Laboratory, Box: 534, Uppsala University, \\ SE-75121 Uppsala, Sweden; mats.leijon@angstrom.uu.se \\ * Correspondence: deepak.soman@angstrom.uu.se
}

Received: 5 April 2017; Accepted: 21 June 2017; Published: 25 June 2017

\begin{abstract}
When medium- or high-voltage power conversion is preferred for renewable energy sources, multilevel power converters have received much of the interest in this area as methods for enhancing the conversion efficiency and cost effectiveness. In such cases, multilevel, multi-input multi-output (MIMO) configurations of DC-DC converters come to the scenario for integrating several sources together, especially considering the stringent regulatory needs and the requirement of multistage power conversion systems. Considering the above facts, a three-level dual input dual output (DIDO) buck-boost converter, as the simplest form of MIMO converter, is proposed in this paper for DC-link voltage regulation. The capability of this converter for cross regulating the DC-link voltage is analyzed in detail to support a three-level neutral point clamped inverter-based grid connection in the future. The cross-regulation capability is examined under a new type of pulse delay control (PDC) strategy and later compared with a three-level boost converter (TLBC). Compared to conventional boost converters, the high-voltage three-level buck boost converter (TLBBC) with PDC exhibits a wide controllability range and cross regulation capability. These enhanced features are extremely important for better regulating variable output renewable energy sources such as solar, wind, wave, marine current, etc. The simulation and experimental results are provided to validate the claim.
\end{abstract}

Keywords: dual input dual output (DIDO) converter; three-level buck boost converter (TLBBC); pulse delay control (PDC); neutral point clamped inverter; cross-regulation; renewable energy conversion

\section{Introduction}

DC-DC converters have been widely used or proposed for different applications, recently for grid-tied renewable power conversion systems [1-4]. For the most part their applications are projected for photovoltaic (PV) systems [5-8]. However, they can be adopted for use with any renewable energy sources that have a DC-conversion stage. Since the power transmission from distant or offshore renewables is efficient in medium or high voltage, conventional converter topologies are replaced by their multilevel counterparts. This power transfer is often fulfilled by multiple power conversion stages. The DC-DC converters regulate the DC-link voltage in common DC-link systems. The normal boost operation used for supporting neutral point clamped (NPC) inverters in grid-connected photovoltaic systems can be replaced with multilevel DC-DC converters for improving the overall performance of the system. In addition, they play a key role in resolving the drawbacks of certain multilevel inverter topologies. For example, many topologies are subjected to circulating current or capacitor voltage imbalance problems. These issues can either be solved by modulation strategies or by additional hardware circuits. Several DC-DC converter configurations are proposed for voltage balancing [9-15]. A three-level boost converter with a new PDC strategy is proposed for the DC-link voltage regulation and neutral point voltage balancing for three-level neutral point clamped (NPC) inverter; see [13,14]. 
In [14], the improvement in converter cross-regulation capability with PDC for TLBC is compared to the conventional three-level boost control and enhancements are listed clearly.

In many renewable energy conversion scenarios, the generated voltage output can become higher or lower than the rated DC-link voltage of the power converter system. In such cases, it is vital to have both buck and boost capabilities for the DC-DC converter to maximize the system utilization. In such situations, the conventional boost and the TLBC become inadequate. Considering the above aspects, the current work proposes DIDO-type TLBBC with a PDC strategy for enhanced power conversion and balancing performance.

Section 2 discusses the basic TLBBC circuit with its four distinct operating modes and characteristics. Ten different operational cases of TLBBC and their contributions for voltage cross regulation, along with the equations for neutral voltage calculation in each case is presented in Section 3. Validation of analytical results using simulations are also presented in this section. A brief discussion of closed-loop controller design is given in Section 4, while the simulation results are presented in Section 5. Cross-regulation comparisons of TLBC and TLBBC are presented with 3D plots in Section 6. In Section 7, experimental setup and test results are described along with a comparison of neutral voltage from analytical, simulation and experimental methods. Final conclusions from the work are presented in Section 8.

\section{Three-Level Buck-Boost Converter-Modes of Operation}

This section discusses about the basic TLBBC circuit with the four operating modes [16], as shown in Figure 1. Depending on the position of the switches S1 and S2, there are four modes of operation for the TLBBC: mode1, mode2, mode3, and mode4. Each mode of operation with corresponding voltage and current equations are presented below, where $p$ denotes the time derivative $d / d t$. Figure 1 shows the current paths during each mode in red.

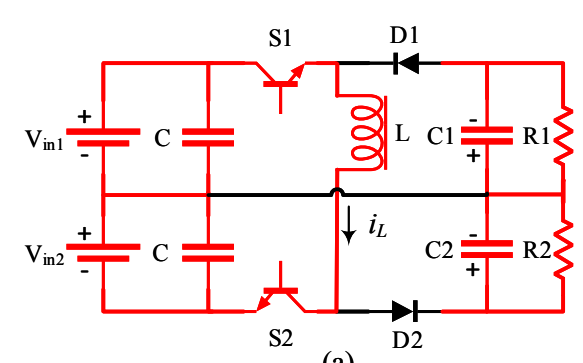

(a)

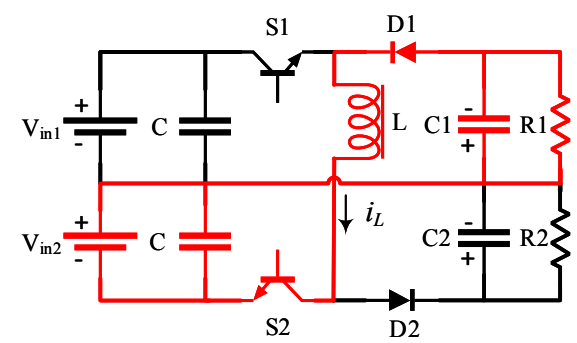

(c)

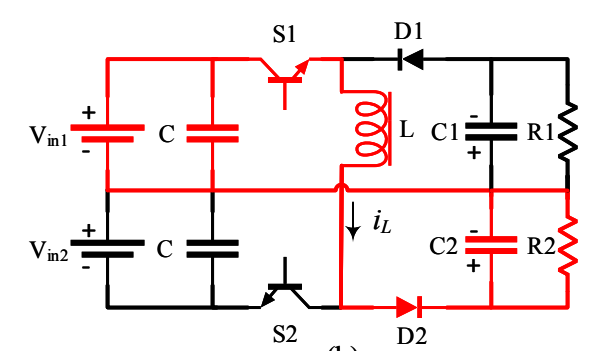

(b)

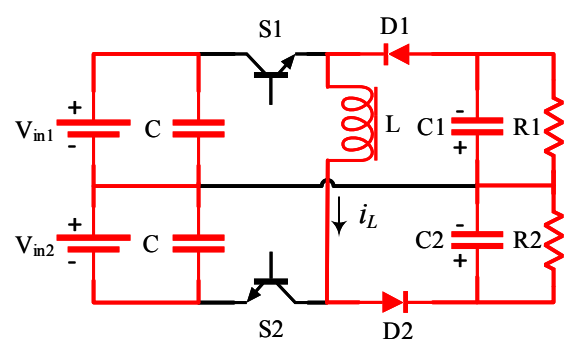

(d)

Figure 1. Three-level buck boost converter (TLBBC) circuit with four operating modes based on the switching states of the switches S1 and S2, defined as mode1 to mode4: (a) Mode1: S1 and S2 ON, (b) Mode2: S1 ON and S2 OFF, (c) Mode3: S1 OFF and S2 ON, (d) Mode4: S1 and S2 OFF.

\subsection{Mode1: S1 and S2 ON}

In Mode1, both $\mathrm{S} 1$ and $\mathrm{S} 2$ are ON. The inductor $L$ is charged by the sources, $V_{\text {in } 1}$ and $V_{\text {in } 2}$ and hence the current via inductor, $i_{L}$, increases linearly. The capacitors $C 1$ and $C 2$ discharge through load 
resistors R1 and R2, as shown in Figure 1a. The steady state voltage and current Equations are given by Equation (1):

$$
p i_{L}=\frac{V_{i n 1}+V_{i n 2}}{L} ; p v_{C 1}=-\frac{v_{C 1}}{\mathrm{R}_{1} \mathrm{C}_{1}} ; p v_{C 2}=-\frac{v_{C 2}}{\mathrm{R}_{2} \mathrm{C}_{2}}
$$

where $v_{\mathrm{C} 1}$ and $v_{\mathrm{C} 2}$ are the voltages across the capacitors $\mathrm{C} 1$ and $\mathrm{C} 2$, respectively, and $\mathrm{R} 1$ and $\mathrm{R} 2$ are the load resistors.

\subsection{Mode2: S1 ON and S2 OFF}

In Mode2, $\mathrm{S} 1$ remains ON whereas S2 is turned OFF, as shown in Figure $1 \mathrm{~b}$. The inductor $L$ is charged by the source, $V_{i n}$ and current flows from input via inductor $L$ to resistor $\mathrm{R} 2$. The capacitor $\mathrm{C} 2$ is charged whereas $\mathrm{C} 1$ discharges through resistor R1. The voltage across $\mathrm{C} 1$ decreases and that of C2 increases, and thereby creates an imbalance at the output. The steady state Equations are given by Equation (2):

$$
p i_{L}=\frac{V_{i n 1}-v_{C 2}}{L} ; p v_{C 1}=-\frac{v_{C 1}}{\mathrm{R}_{1} \mathrm{C}_{1}} ; p v_{C 2}=\frac{i_{L} \mathrm{R}_{2}-v_{C 2}}{\mathrm{R}_{2} \mathrm{C}_{2}}
$$

\subsection{Mode3: S1 OFF and S2 ON}

This mode is quite like the previous mode. The current flows from input $V_{\text {in } 2}$ via inductor $L$ to resistor R1. The capacitor $\mathrm{C} 1$ is charged while $\mathrm{C} 2$ discharges through resistor R2. In this mode, the voltage across $\mathrm{C} 1$ increases and $\mathrm{C} 2$ decreases, resulting in an imbalance. The flow of current is shown in Figure 1c. The steady state Equations are given by Equation (3):

$$
p i_{L}=\frac{V_{i n 2}-v_{C 1}}{L} ; p v_{C 1}=\frac{i_{L} \mathrm{R}_{1}-v_{C 1}}{\mathrm{R}_{1} \mathrm{C}_{1}} ; p v_{C 2}=-\frac{v_{C 2}}{\mathrm{R}_{2} \mathrm{C}_{2}} .
$$

\subsection{Mode4: S1 and S2 OFF}

If both $\mathrm{S} 1$ and $\mathrm{S} 2$ are OFF, then there is no direct energy transfer from source to load. The inductor $L$ discharges to the load and, hence, the current $i_{L}$ decreases linearly. There will not be any unbalanced voltage at the output. The flow of current is shown in Figure 1d. The state space Equations are given by Equation (4):

$$
p i_{L}=\frac{v_{C 1}+v_{C 2}}{L} ; p v_{C 1}=\frac{i_{L} R_{1}-v_{C 1}}{R_{1} C_{1}} ; p v_{C 2}=\frac{i_{L} R_{2}-v_{C 2}}{R_{2} C_{2}}
$$

form the modes of operation listed above; it is clear that the TLBBC has different characteristics during each mode. The modes 1 and 4 are primarily responsible for the conventional buck-boost type converter operation, while the modes 2 and 3 are capable for the cross-regulation/voltage balancing.

\section{Operational Cases, Open-Loop Control Equations and Cross-Regulation Verification}

From the detailed analysis of TLBBC operation using different combination, sequencing and timing of TLBBC operating modes, it is found that the converter can go through 10 different operational cases during its entire range of operation as shown in Table 1. The analysis is based on the assumption that the converter stays in continuous current mode (CCM) during all the cases of operation. These cases can be used for the mathematical modeling of the DC-link voltage and thereby enable the design of the controller. The inductor ripple current is different in each case. Therefore, the conventional state space averaging technique cannot be applied to all the cases. The inductor ripple current averaging technique with state space averaging method is the best suited [14,17]. Using this method, the voltage difference $\Delta V$ for each case is modeled. Table 1 also gives the expression of $\Delta V$ for all 10 cases of operation of the TLBBC.

It should be noted that the case I and case IV with only two modes of operation in each case will not be able to contribute for cross regulation purposes. However, they can be used for the normal buck-boost operation. In particular, case I, which includes mode1 and mode4, is similar to 
the conventional buck-boost converter operation and can be used for the total voltage control of the TLBBC output by using a duty ratio control similar to the conventional buck-boost regulation. Case IV is, however, not present in the conventional converter, and it charges and discharges the two capacitors equally during alternative switching modes. This causes the average voltage change in a cycle to become zero and cannot contribute to cross-regulation application. All the other cases, except case I and case IV, can contribute to cross-regulation purposes, and the intelligent use of these cases during closed loop control of TLBBC can enhance the cross-regulation capabilities of the TLBBC while optimizing the performance and stability.

Table 1. TLBBC operational cases and expressions for neutral voltage.

\begin{tabular}{ccc}
\hline Cases & Mode Sequencing & $\Delta \boldsymbol{V}$ \\
\hline I & mode $1 \rightarrow$ mode4 & 0 \\
II & mode $1 \rightarrow$ mode $3 \rightarrow$ mode $4 \rightarrow$ mode2 & $-\lambda[\lambda-2 d(1-d)] \Theta$ \\
III & mode $\rightarrow$ mode $\rightarrow$ mode $4 \rightarrow$ mode3 & $(1-\lambda)(2 d(d-1)+1-\lambda) \Theta$ \\
IV & mode $2 \rightarrow$ mode3 & 0 \\
V & mode $1 \rightarrow$ mode2 $\rightarrow$ mode3 & $-(2 d-1)(1-d)^{2} \Theta$ \\
VI & mode $1 \rightarrow$ mode3 $\rightarrow$ mode1 $\rightarrow$ mode2 & $(2 \lambda-1)(1-d)^{2} \Theta$ \\
VII & mode1 $\rightarrow$ mode3 $\rightarrow$ mode2 & $-\lambda^{2}(1-2 \lambda) \Theta$ \\
VIII & mode2 $\rightarrow$ mode4 $\rightarrow$ mode3 & $(1-2 \lambda)(1-\lambda)^{2} \Theta$ \\
IX & mode2 $\rightarrow$ mode4 $\rightarrow$ mode3 $\rightarrow$ mode4 & $(1-2 \lambda) d^{2} \Theta$ \\
$X$ & mode2 $\rightarrow$ mode3 $\rightarrow$ mode4 & $\lambda^{2}(1-d-\lambda) \Theta$ \\
\hline
\end{tabular}

Where $d$ is the duty ratio of the switches, $\lambda$ is the pulse delay ratio (delay between switch gate pulses/switching period) and $\Theta$ is a function of input and output voltages, which is defined in Equation (5):

$$
\Theta=\frac{R T_{s}}{2 L}\left[v_{C 1}+v_{C 2}+V_{i n 1}+V_{i n 2}\right]
$$

The voltage imbalance, $\Delta V$, obtained mathematically, can be compared with the value given by the simulation for each case. Figure 2 shows the value of $\Delta V$ obtained from calculation and in open-loop simulation. It is shown that both the results are almost equal. The simulation parameters used are given in Table 2.

Table 2. Simulation parameters.

\begin{tabular}{cc}
\hline Parameter Name & Value \\
\hline Input voltages $V_{i n 1}, V_{i n 2}$ & $25 \mathrm{~V}$ \\
Switching frequency, $f_{s}$ & $5 \mathrm{kHz}$ \\
Input capacitance, $\mathrm{C}$ & $5 \mathrm{mF}$ \\
Inductor, $L$ & $200 \mu \mathrm{H}$ \\
Output capacitance, $\mathrm{C}_{1}, \mathrm{C}_{2}$ & $1 \mathrm{mF}$ \\
Load resistance, $\mathrm{R}_{1}, \mathrm{R}_{2}$ & $2 \Omega$ \\
$V_{\text {forward }}[$ insulated gate bipolar transistor & $1 \mathrm{mV}$ \\
(IGBT) and diode] & \\
\hline
\end{tabular}




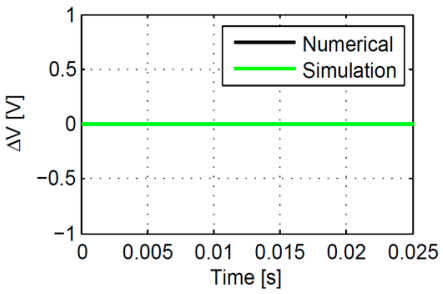

(a)

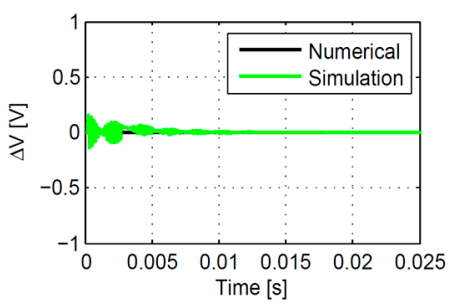

(d)

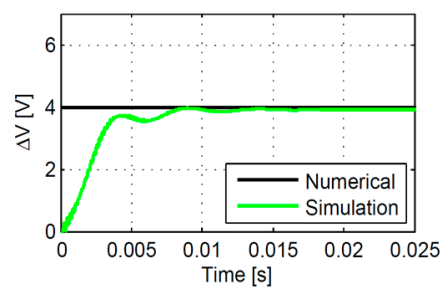

(g)

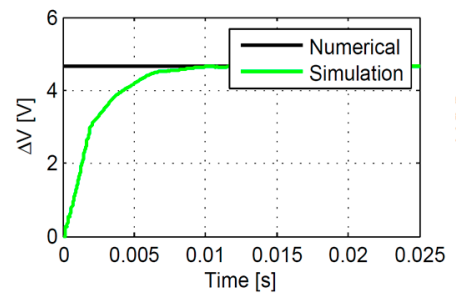

(b)

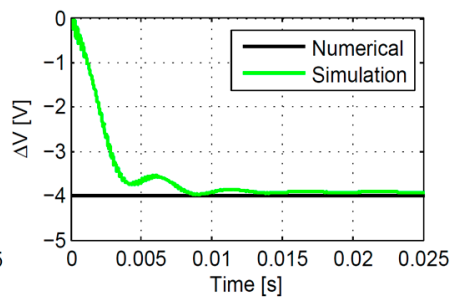

(e)

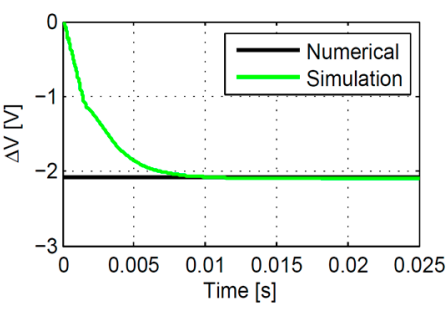

(h)

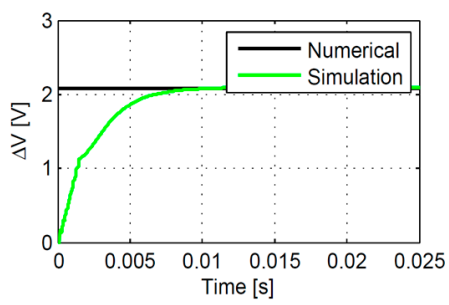

(j)

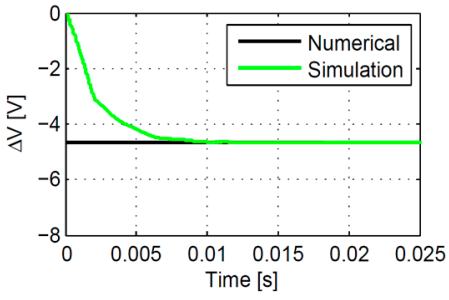

(c)

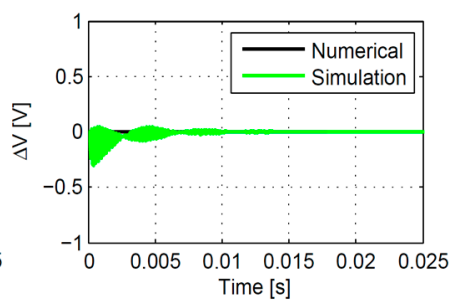

(f)

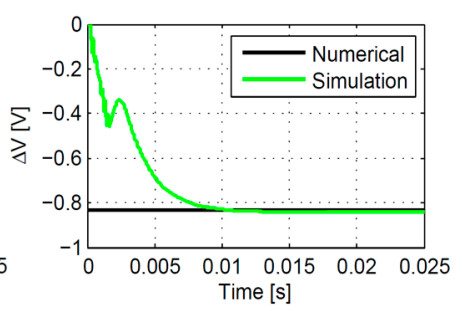

(i)

Figure 2. The voltage imbalance $\Delta V$ from mathematical analysis and simulations, corresponding to each operational cases of TLBBC: (a) Case 1; (b) Case 2; (c) Case 3; (d) Case 4; (e) Case 5; (f) Case 6; (g) Case 7; (h) Case 8; (i) Case 9; (j) Case 10.

\section{Closed-Loop Controller Modelling}

The DC-link voltage regulation is carried out by using the buck-boost capability of the system very similar to the conventional buck-boost converter control. The steady state output voltage, $V_{0}$, of the buck-boost converter can be calculated using the input voltage, $V_{i n}$, and the duty ratio, $d$, as shown in Equation (6). Depending on the value of $d$, the converter either increases or decreases the voltage given to the input.

$$
V_{0}=V_{\text {in }} \frac{d}{(1-d)}
$$


To get the desired output voltage for a varying source voltage, the duty ratio must be controlled. The proportional integral (PI) controller computes the value of duty ratio, $d$, required for achieving the desired output voltage. The Equation of the controller for voltage regulation is given by (7):

$$
d=k_{p 1} e_{v}+k_{i 1} \int e_{v} d t
$$

where $k_{p 1}$ and $k_{i 1}$ are the proportional and integral controller parameters, and the error, $e_{v}=V_{r e f}-V_{0}$; $V_{r e f}$, is the desired DC-link voltage, and $V_{0}$ is the actual output voltage.

In TLBBC, the two switches are operated with the same duty ratio. The phase between the control signals of the switches is varied to minimize the neutral point voltage ideally to zero. The gate signal of one switch is kept constant, while the phase of the other signal is varied. The voltage deference between the output capacitors, $\Delta V$, is sensed and is used in a PI controller to calculate a pulse delay ratio, as shown in Equation (8). This delay is given to one of the switch pulse signal to move it either forward or backward with respect to the other pulse signal in order to compensate for the neutral point voltage.

$$
\lambda=k_{p 2} e_{\Delta v}+k_{i 2} \int e_{\Delta v} d t
$$

where $k_{p 2}$ and $k_{i 2}$ are the PI controller parameters, $e_{\Delta v}=\Delta V_{r e f}-\Delta V$.

Applying perturbations to the state variables, the expression of the neutral point voltage for AC analysis can be formulated. Considering case 2 for illustration, the system transfer function is given as shown in Equation (9):

$$
G=\frac{\widetilde{\Delta V}}{\lambda}=\frac{[2 d(1-d)-2 \lambda] V_{i n} T}{2(1-d) L C\left(s+\frac{1}{\mathrm{RC}}\right)}
$$

where $T$ is the switching period. Since a PI controller is used, the closed-loop transfer function $G_{c}$ is given by Equation (10):

$$
G_{c}=\left(k_{p 2}+\frac{k_{i 2}}{s}\right) \frac{[2 d(1-d)-2 \lambda] V_{i n} T}{2(1-d) L C\left(s+\frac{1}{\mathrm{RC}}\right)}
$$

To find the value of $k_{p 2}$ and $k_{i 2}$, equate the characteristic equation of (10) to zero. The controller can be tuned using these values. For example, in case II, the values of $k_{p 2}$ and $k_{i 2}$ are 0.1596 and 33.9605, respectively. It is observed that the same value of $k_{p 2}$ and $k_{i 2}$ satisfies other cases of the operation of the TLBBC as well. The simulation results show the maximum values of $\Delta V$ that the system can achieve with the feasible values of $d$ and $\lambda$.

\section{Simulation Results}

Depending on the switching states, the TLBBC can be operated either as a normal buck-boost converter or as a cross-voltage compensator. The operating regions of the converter are determined by the duty ratio of the switch-gate signals and the pulse delay between them. Duty ratio is used for conventional buck-boost action and pulse delay gives the voltage cross regulation. To analyze these operations, the TLBBC circuit is simulated for a switching frequency of $5 \mathrm{kHz}$ in MATLAB/Simulink under ideal conditions. Table 2 shows the specifications used for the simulations. For a step variation of the reference voltage $\Delta V$ from $1 \mathrm{~V}$ to $3.9 \mathrm{~V}$, the system follows the input and gives the maximum response. The corresponding pulse delay ratio is just below 0.25 . Figure 3 shows the corresponding waveforms. The settling time is $0.03 \mathrm{~s}$. For values greater than or equal to $4 \mathrm{~V}$, the converter saturates and the system starts oscillating, as shown in Figure 4a. The corresponding pulse delay variation is shown in Figure $4 b$. 


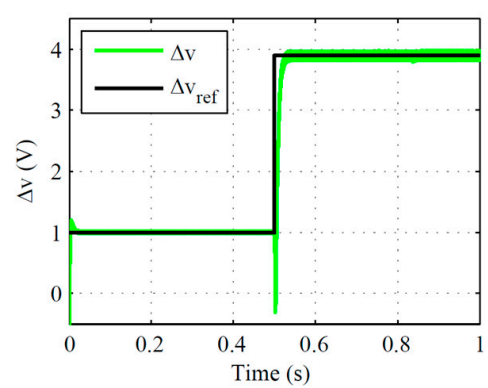

(a)

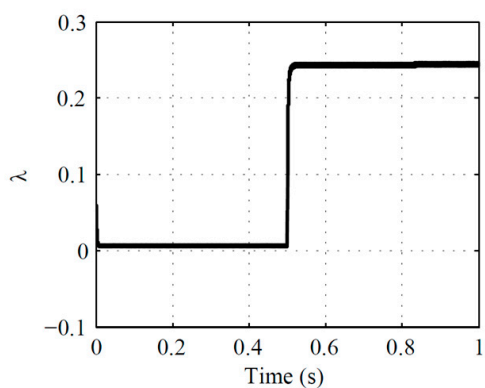

(b)

Figure 3. Maximum values of (a) capacitor voltage imbalance $\Delta V$, and (b) corresponding pulse delay ratio $\lambda$.

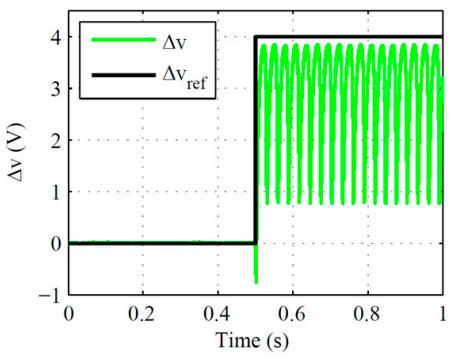

(a)

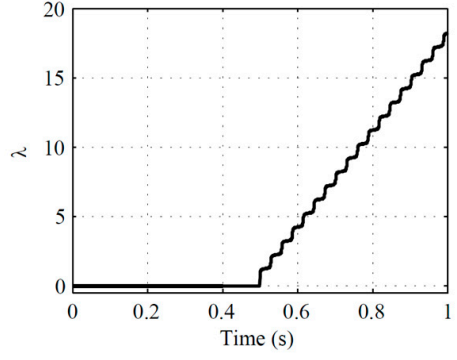

(b)

Figure 4. Values on controller saturation (a) capacitor voltage difference $\Delta V$, and (b) pulse delay ratio $\lambda$.

\section{Comparison with Three-Level Boost Converter}

The cross-regulation capabilities of a TLBBC and a three-level boost converter (TLBC) are compared under the PDC control method. The maximum cross-regulation voltages are calculated for all the 10 cases. The corresponding 3D-plots are shown below. For TLBC, the maximum normalized cross-regulation voltage is \pm 0.0625 ; see Figure 5. For TLBBC, this value is \pm 0.1467 ; see Figure 6 . It shows that the TL buck-boost converter has better cross-regulation capability compared to the TL boost converter under same cross-voltage regulation method.

The cross-regulation voltage values in the figures below indicate the theoretical maximum for each duty ratio and pulse delay ratio. However, in practical scenarios, these values can be lower than that calculated here. The peracetic drops, the component lead impedances and losses in the switches and diodes restrict the converter to achieve these peak values. The parameters used for this simulation is also the same as the parameters used for the previous simulations and listed in Table 2.

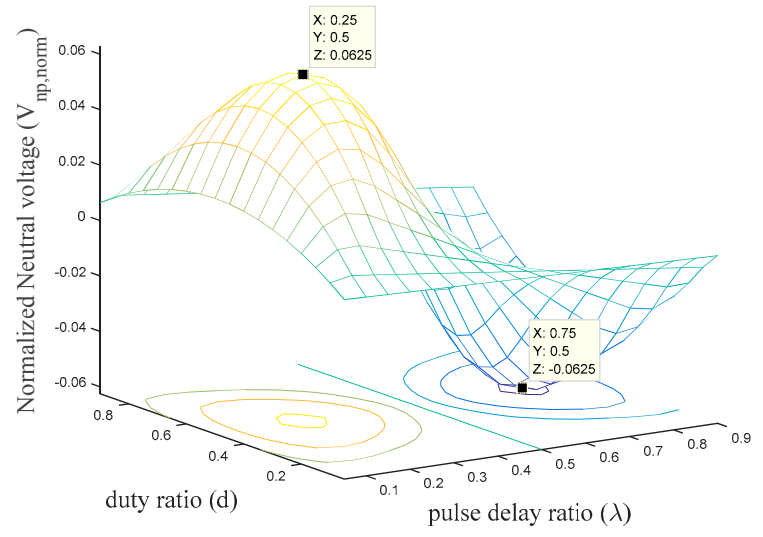

Figure 5. Normalized cross-regulation voltage for three-level boost converter. 


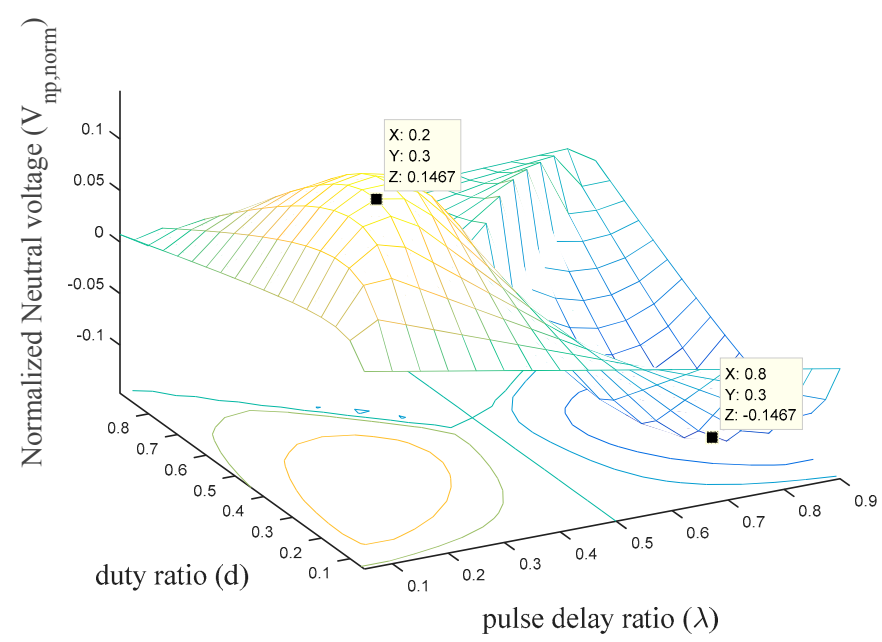

Figure 6. Normalized cross-regulation voltage for three-level buck-boost converter.

\section{Experimental Results}

The converter design mainly consists of the selection of IGBT modules. The IGBT module BSM50GB120DN2 from Infineon is used as the switches. It is a high-power module and can handle high voltages of up to $1200 \mathrm{~V}$. The free-wheeling diodes in the module are used as the diodes of the converter circuit. An air-gapped ferrite core with copper winding is used as inductor. Snubbers and varistors are also included to protect the circuit from high voltages and transient peaks. The experimental setup of the converter hardware is shown in Figure 7. The input voltages, the output capacitor voltages and the cross-regulation performance of the converter results from the experiment for boost and buck mode is shown in Figure 8.

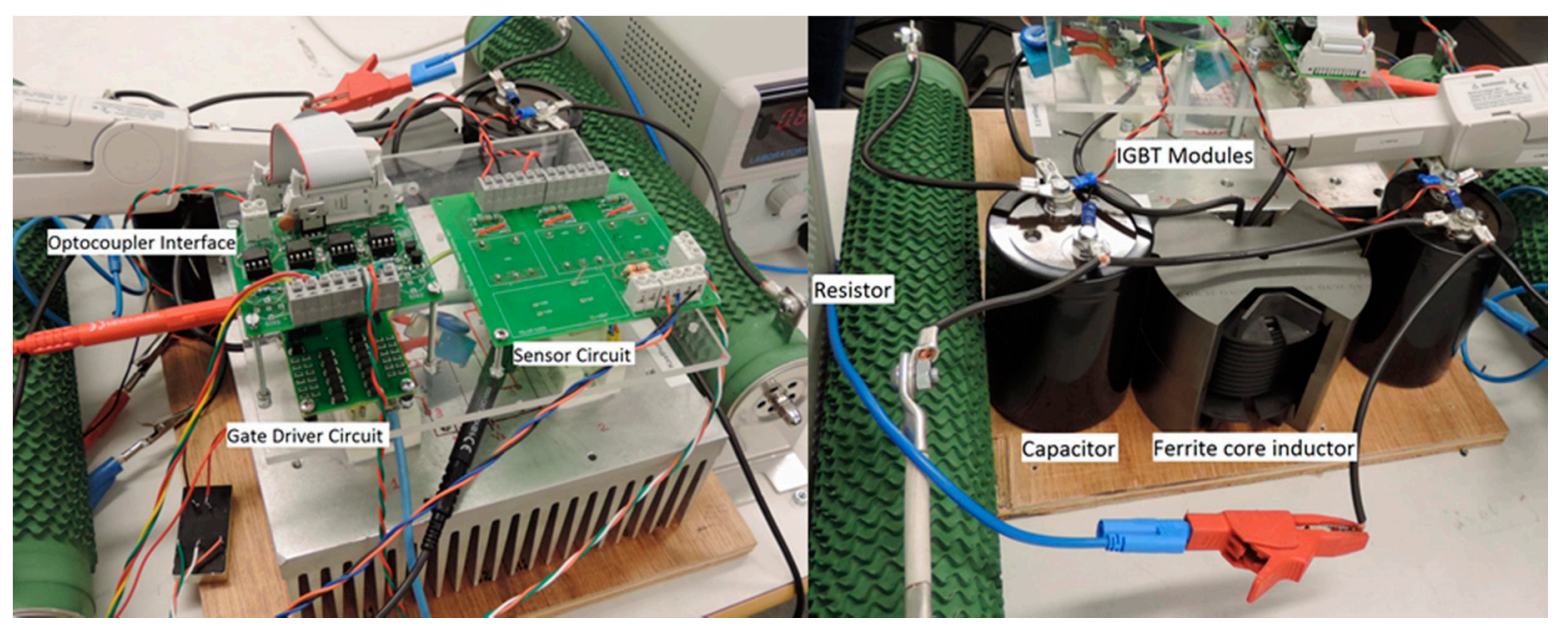

Figure 7. Hardware set-up for TLBBC. 

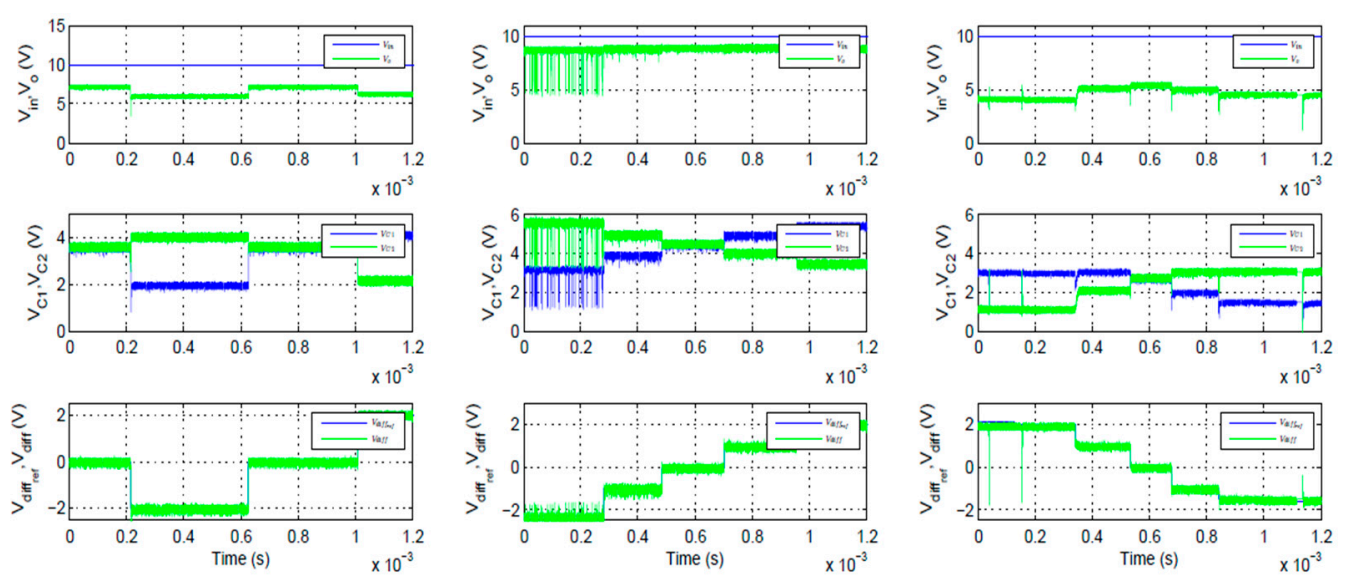

(a)

(b)

(c)

Figure 8. Closed loop operation: input and output voltages, capacitor voltages and system response waveforms when (a) $d=0.5$, (b) boost mode, $d=0.6$, and (c) buck mode, $d=0.4$.

In Figure 9, the cross-regulation voltages in calculation, simulation and experiment are compared. The mathematical analysis and simulation results give very similar results while the experimental results are slightly lower. This is due to the losses present in the converter hardware which are not present in the analytical and simulated results assuming ideal conditions.

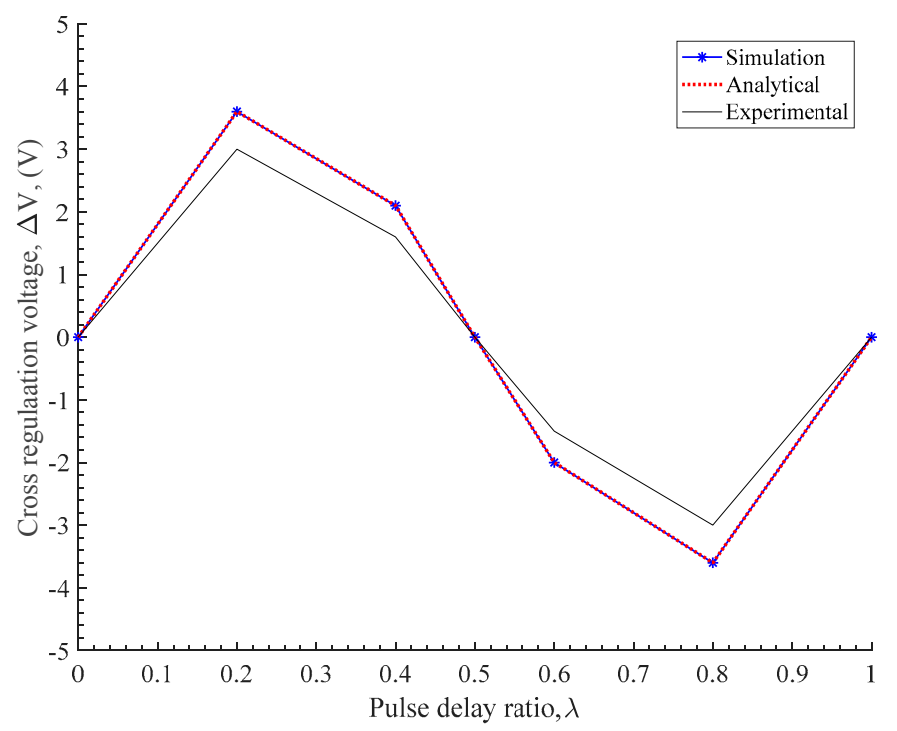

Figure 9. A comparison of $\Delta \mathrm{V}$ from analytical, simulation, and experimental results.

\section{Conclusions}

The three-level buck-boost converter is analyzed to find the amount of cross-regulation it can provide. This analysis is significant for various renewable energy grid integration scenarios where the three-level NPC inverter is used for grid coupling. Varying input from renewable sources imposes high-input cross-regulation requirements for the NPC. A new type of PDC cross-regulation method is proposed to compensate for the imbalance produced at the NPC input. Different operating modes of the TLBBC circuit are analyzed and 10 cases of operation are found, which can be used to control efficiently the maximum possible oprating range of the converter. The expression for the voltage imbalance for each case is formulated using ripple current averaging method. Moreover, the simulation 
in Matlab/simulink validates the voltage imbalance created in each of these 10 cases. A closed-loop controller using PI controllers is designed based on the operatinal case equations in order to achieve the desired voltage compensation. When PDC and convensional duty ratio controls are combined, the converter gives full performance by providing both output voltage control, as well as cross regulation. The cross-regulation capability of the TLBBC converter is compared to the TLBC converter to show its superiority in cross regulation. The simulation results are verified using experimental results. The results shows that the TLBBC has a better cross-regulation capability, which can be really useful to support three-level NPC based renewable grid integration. In this study, the input voltages are considered as equal. However, it would be of interest to see the converter feasibility with unequal input voltage. This is considered as an area future study.

Acknowledgments: This work is funded by SweGRIDS-Swedish Centre for Smart Grids and Energy Storage. The authors would like to thank European Institute of Innovation and Technology (EIT) KIC InnoEnergy, Swedish Energy Agency and 'STandUP for Energy' for their support.

Author Contributions: First author Deepak Elamalayil Soman has written the paper and performed the experiments under the supervision of second author Mats Leijon.

Conflicts of Interest: The authors declare no conflict of interest.

\section{References}

1. Carrasco, J.M.; Franquelo, L.G.; Bialasiewicz, J.T.; Galvan, E.; Portillo, R.; Prats, M.M.; Leon, J.I.; Moreno, N. Power-Electronic Systems for the Grid Integration of Renewable Energy Sources: A Survey. IEEE Trans. Ind. Electron. 2006, 53, 1002-1016. [CrossRef]

2. Singaravel, M.M.R.; Daniel, S.A. MPPT with Single DC-DC Converter and Inverter for Grid-Connected Hybrid Wind-Driven PMSG-PV System. IEEE Trans. Ind. Electron. 2015, 62, 4849-4857. [CrossRef]

3. Hartnett, K.J.; Hayes, J.G.; Rylko, M.S.; Barry, B.J.; Maslon, J.W. Comparison of 8-kW CCTT IM and Discrete Inductor Interleaved Boost Converter for Renewable Energy Applications. IEEE Trans. Ind. Appl. 2015, 51, 2455-2469. [CrossRef]

4. Yaramasu, V.; Wu, B.; Rivera, M.; Rodriguez, J. A New Power Conversion System for Megawatt PMSG Wind Turbines Using Four-Leve Simple Control Scheme Based on Two-Step Model Predictive Strategy-Part I: Modeling and Theoretical Analysis. IEEE J. Emerg. Sel. Top. Power Electron. 2014, 2, 3-13. [CrossRef]

5. Errouissi, R.; Al-Durra, A.; Muyeen, S.M. A Robust Continuous-Time MPC of a DC-DC Boost Converter Interfaced with a Grid-Connected Photovoltaic System. IEEE J. Photovolt. 2016, 6, 1619-1629. [CrossRef]

6. Das, M.; Agarwal, V. Novel High-Performance Stand-Alone Solar PV System with High-Gain High-Efficiency DC-DC Converter Power Stages. IEEE Trans. Ind. Appl. 2015, 51, 4718-4728. [CrossRef]

7. Jamshidpour, E.; Poure, P.; Saadate, S. Photovoltaic Systems Reliability Improvement by Real-Time FPGA-Based Switch Failure Diagnosis and Fault-Tolerant DC-DC Converter. IEEE Trans. Ind. Electron. 2015, 62, 7247-7255. [CrossRef]

8. Maity, S.; Sahu, P.K. Modeling and Analysis of a Fast and Robust Module-Integrated Analog Photovoltaic MPP Tracker. IEEE Trans. Power Electron. 2016, 31, 280-291. [CrossRef]

9. Tan, L.; Wu, B.; Yaramasu, V.; Rivera, S.; Guo, X. Effective Voltage Balance Control for Bipolar-DC-Bus-Fed EV Charging Station with Three-Level DC-DC Fast Charger. IEEE Trans. Ind. Electron. 2016, 63, 4031-4041. [CrossRef]

10. Krishna, R.; Kottayil, S.K.; Leijon, M. Predictive Current Controller for a Grid Connected Three Level Inverter with Reactive Power Control. In Proceedings of the 2010 IEEE 12th Workshop on Control and Modeling for Power Electronics (COMPEL), Boulder, CO, USA, 28-30 June 2010; pp. 1-6.

11. Yaramasu, V.; Wu, B. Predictive Control of a Three-Level Boost Converter and an NPC Inverter for High-Power PMSG-Based Medium Voltage Wind Energy Conversion Systems. IEEE Trans. Power Electron. 2014, 29, 5308-5322. [CrossRef]

12. Filba-Martinez, A.; Busquets-Monge, S.; Nicolas-Apruzzese, J.; Bordonau, J. Operating Principle and Performance Optimization of a Three-Level NPC Dual-Active-Bridge DC-DC Converter. IEEE Trans. Ind. Electron. 2016, 63, 678-690. [CrossRef] 
13. Vitoi, L.A.; Krishna, R.; Soman, D.E.; Leijon, M.; Kottayil, S.K. Control and Implementation of Three Level Boost Converter for Load Voltage Regulation. In Proceedings of the 39th Annual Conference of the IEEE Industrial Electronics Society (IECON), Vienna, Austria, 10-13 November 2013; pp. 561-565.

14. Krishna, R.; Soman, D.E.; Kottayil, S.K.; Leijon, M. Pulse Delay Control for Capacitor Voltage Balancing in a Three-Level Boost Neutral Point Clamped Inverter. IET Power Electron. 2015, 8, 268-277. [CrossRef]

15. Soman, D.E.; Krishna, R.; Leijon, M.; Vikram, K.; Kottayil, K.; Vitoi, L.A.; Oliveira, J.G.; Kumar, S.S. Discontinuous Conduction Mode of a Three-Level Boost DC-DC Converter and Its Merits and Limits for Voltage Cross Regulation Applications. In Proceedings of the 40th Annual Conference of the IEEE Industrial Electronics Society (IECON), Dalas, TX, USA, 29 October-1 November 2014; pp. 4268-4272.

16. Soman, D.E.; Vikram, K.; Krishna, R.; Gabrysch, M.; Kottayil, S.K.; Leijon, M. Analysis of Three-Level Buck-Boost Converter Operation for Improved Renewable Energy Conversion and Smart Grid Integration. In Proceedings of the 2014 IEEE International Energy Conference (ENERGYCON), Cavtat, Croatia, 13-16 May 2014; pp. 76-81.

17. Davoudi, A.; Jatskevich, J.; Rybel, T.D. Numerical State-Space Average-Value Modeling of PWM DC-DC Converters Operating in DCM and CCM. IEEE Trans. Power Electron. 2016, 21, 1003-1012. [CrossRef]

(C) 2017 by the authors. Licensee MDPI, Basel, Switzerland. This article is an open access article distributed under the terms and conditions of the Creative Commons Attribution (CC BY) license (http:/ / creativecommons.org/licenses/by/4.0/). 